\title{
A STATISTICAL APPROACH TO IBNR-RESERVES IN MARINE REINSURANCE*
}

\author{
By JoAKIM Hertig
}

Baltica-Nordisk Re, Copenhagen

\begin{abstract}
The run off-pattern of long-term reinsurance treaties is described by means and standard deviations of logarithmic increments of premiums and loss ratios in a normal distribution. From this description forecasts of ultimate claims and current IBNR-reserves are derived, with associated distributions and confidence limits. Aggregation from individual treaties to portfolio level is proposed by normal approximation. Security loading of IBNR-reserves is proposed by a contingency reserve at portfolio level.
\end{abstract}

\section{KEYWORDS}

Run off pattern, lognormal distribution, IBNR reserves, contingency reserves, marine reinsurance.

\section{INTRODUCTION}

The present work forms part of a project to improve rules for the establishment of technical reserves in the B-N Re. Particular problems arise in the area of long tail insurance, where claims occur years after expiration of the risk period. This problem of IBNR-reserving has been treated by several authors in recent years, with the common approach to estimate ultimate claims from which current reserves are derived. TAYLOR (1977) separates components of inflation and real development by calculational methods, and provides a deterministic forecast. BühlmanN, SChNiEPer and Straub (1980) introduces a probabilistic model, proposing a lognormal distribution of the percentage increment from one year to the next. KREMER (1982) proposes an ANOVA-approach with future values of claims treated as missing values, also using a lognormal distribution. In the present work, a main objective was the establishment of an operational tool for underwriters without formal statistical background. Another objective was the establishment of confidence limits of reserves, at single treaty level as well as portfolio level. To meet these objectives, effective use of simple statistical methods, and simple identification of key variables, were emphasized rather than deep theoretical considerations. The resulting model applies univariate normal theory to the logarithmic increments from one development year to the next, sharing basic assumptions with the papers of Bühlmann, Schnieper and Straub, and of

*A previous version of this paper was presented to the Astin colloqium at Lindau, Germany, October 1983. 
Kremer. Below, the approach is developed with statement of the IBNR-problem, definition of model variables, estimation procedure, testing parameter stability, forecasting ultimate premiums and claims, and thus establishment of the IBNRreserve for a single reinsurance treaty. The method is demonstrated on an example treaty. From single treaty level aggregation to portfolio level is performed by use of normal approximation, and at portfolio level a further security loading or contingency reserve is provided through the confidence limit.

\section{THE IBNR-PROBLEM}

Long tail (non-life) insurance emanates from policies covering a period of usually one year, the claims being reported and settled during a longer period. The main areas of long tail insurance are marine insurance, where ships often sail with damages for several years until docked, and liability insurance where events covered may be discovered after several years and court negotiations add further to the duration. The insurer operating in these fields finds it difficult to quote adequate and competetive rates taking recent experience into account, and also

TABLE I

Development of a Marine Reinsurance Treaty

(Thousand DKK)

\begin{tabular}{|c|c|c|c|c|c|}
\hline \multirow{2}{*}{\multicolumn{2}{|c|}{ Underwriting Year }} & \multicolumn{4}{|c|}{ Financial Year } \\
\hline & & \multirow{2}{*}{$\frac{1975}{310}$} & \multirow{2}{*}{$\frac{1976}{288}$} & \multirow{2}{*}{$\begin{array}{c}1977 \\
31\end{array}$} & \multirow{2}{*}{$\begin{array}{r}1978 \\
-5\end{array}$} \\
\hline 1975 & Premium & & & & \\
\hline & Commission & 85 & 80 & 8 & -1 \\
\hline & Claims paid & 31 & 239 & 147 & 34 \\
\hline & Claims outstanding & 167 & 152 & 36 & 15 \\
\hline & Profit/Loss & 26 & -16 & -8 & -17 \\
\hline \multirow[t]{5}{*}{1976} & Premium & & 310 & 289 & 30 \\
\hline & Commission & & 85 & 80 & 8 \\
\hline & Claims paid & & 39 & 262 & 170 \\
\hline & Claims outstanding & & 165 & 135 & 67 \\
\hline & Profit/Loss & & 21 & -23 & -80 \\
\hline \multirow[t]{5}{*}{1977} & Premium & & & 345 & 322 \\
\hline & Commission & & & 95 & 88 \\
\hline & Claims paid & & & 86 & 368 \\
\hline & Claims outstanding & & & 154 & 136 \\
\hline & Profit/Loss & & & 10 & -116 \\
\hline \multirow{5}{*}{$\begin{array}{l}\text { Financial } \\
\text { year total }\end{array}$} & Premium & 310 & 598 & 665 & 347 \\
\hline & Commission & 85 & 165 & 183 & 95 \\
\hline & Claims paid & 31 & 278 & 495 & 572 \\
\hline & Claims outstanding & 167 & 317 & 325 & 218 \\
\hline & Profit/Loss & 26 & 5 & -21 & -213 \\
\hline
\end{tabular}


meets difficulties in the establishment of loss reserves for past but still vaguely reported underwriting years.

To the reinsurer this problem is intensified, since he obtains no information on individual policies and claims, but usually receives brief quarterly statements on aggregated accounts for a treaty covering a whole portfolio, and a note on aggregate claims outstanding once a year.

Table I demonstrates a reinsurers difficulties.

This representative example is the Baltica share of a European marine reinsurance treaty, covering hull and cargo on a quota share basis. Premiums are received chiefly over two years and claims incur in the second and third year of development with still some considerable adjustments in the fourth and following years. The noted reserves do not suffice, and the reinsurer cannot just rely on reported results and obviously has to reinforce reserves not to carry hidden loses in his books. Experienced underwriters are able to propose reserve reinforcements, but their proposals tend to be individual. This is a problem of Incurred But Not (Enough) Reported $=I B N(E) R$ reserves.

\section{DEFINITION OF KEY VARIABLES}

The basic tool in the analysis of development is the run off triangle, e.g., the triangle of accumulated premiums of the example treaty:

TABLE II

ACCUMulated PRemiums

(Thousand DKK)

\begin{tabular}{|c|c|c|c|c|c|c|}
\hline \multirow{2}{*}{$\begin{array}{c}\text { Underwriting } \\
\text { Year }\end{array}$} & \multicolumn{6}{|c|}{ Development Year } \\
\hline & 1 & 2 & 3 & 4 & 5 & 6 \\
\hline 1969 & & & & & & 226 \\
\hline 1970 & & & & & 261 & 261 \\
\hline 1971 & & & & 329 & 328 & 328 \\
\hline 1972 & & & 434 & 436 & 435 & 435 \\
\hline 1973 & & 610 & 632 & 631 & 630 & 630 \\
\hline 1974 & 420 & 704 & 739 & 738 & 736 & 736 \\
\hline 1975 & 310 & 598 & 629 & 624 & 623 & 622 \\
\hline 1976 & 310 & 599 & 629 & 631 & 629 & \\
\hline 1977 & 345 & 667 & 680 & 679 & & \\
\hline 1978 & 491 & 731 & 737 & & & \\
\hline 1979 & 581 & 815 & & & & \\
\hline 1980 & 577 & & & & & \\
\hline
\end{tabular}

The earliest financial year still kept in the files was 1974 and in 1980 registration procedures were changed, such that the entire story of development was only 
recorded for the underwriting years 1974 and 1975. In line with the findings above, it is seen that the treaty more generally shows a substantial premium growth from the first to the second year of development, a moderate growth from the second to the third year and then only small adjustments.

These observations are more clearly exhibited by the increments between successive development years:

TABLE III

Logarithmic InCRements of Premium

\begin{tabular}{cccccr}
\hline \hline & \multicolumn{5}{c}{ Development Years } \\
\cline { 2 - 6 } \multicolumn{1}{c}{$\begin{array}{c}\text { Underwriting } \\
\text { Years }\end{array}$} & $1 \rightarrow 2$ & $2 \rightarrow 3$ & $3 \rightarrow .4$ & $4 \rightarrow 5$ & $5 \rightarrow 6$ \\
\hline 1970 & & & & & 0.001 \\
1971 & & & 0.003 & -0.001 & -0.001 \\
1972 & & & -0.001 & -0.002 & 0.000 \\
1973 & 0.517 & 0.048 & -0.001 & -0.004 & 0.000 \\
1974 & 0.659 & 0.051 & -0.008 & -0.002 & -0.001 \\
1975 & 0.657 & 0.050 & 0.002 & -0.002 & \\
1976 & 0.660 & 0.019 & -0.001 & & \\
1977 & 0.398 & 0.009 & & & \\
1978 & 0.338 & & & & -0.000 \\
1979 & 0.538 & 0.035 & -0.001 & -0.002 & 0.001 \\
& 0.144 & 0.018 & 0.004 & 0.001 & 5 \\
mean & 5 & 5 & 5 & 5 & 5 \\
std. deviation & & & & &
\end{tabular}

In the project ideas were tested on a set of $\mathbf{4 0}$ marine treaties in order to assess their feasibility, and in all treaties similar stabilities of logarithmic premium increments were present. As the reinsurer does not get further information, only guesses of the causes of the stable patterns can be made. The phenomenon is well known by underwriters and commonly explained by the stability of underlying portfolios. Within these individual shipowners' dates of premium payment are thought to be stable, though rates and inflation may change the premium level from one underwriting year to another. But it appears that development patterns vary between treaties.

Turning toward the development of claims, the central point in relation to IBNR-reserving is the originally noted claims, i.e., accumulated paid claims plus originally noted loss reserves. With decent rating criteria the premium volume will reflect the expected volume of claims, and so the premium and loss developments will be dependent. In modelling key variables should be independent, and the loss quotient, i.e., originally noted claims in relation to accumulated premium, appears to be less dependent on premium than absolute volume of losses. Also, one may note that underwriters traditionally monitor loss developments by loss ratios rather than volume of losses, thus supporting loss ratio as a suitable key variable. 
The loss quotient of the example treaty developed as shown:

TABLE IV

LOSS QUOTIENT

\begin{tabular}{ccccccc}
\hline \hline & \multicolumn{7}{c}{ Development Year } \\
\cline { 2 - 7 } $\begin{array}{c}\text { Underwriting } \\
\text { Year }\end{array}$ & 1 & 2 & 3 & 4 & 5 & 6 \\
\hline 1969 & & & & & & 0.801 \\
1970 & & & & & 0.781 & 0.791 \\
1971 & & & & 0.724 & 0.734 & 0.728 \\
1972 & & & 0.762 & 0.756 & 0.749 & 0.753 \\
1973 & & 0.694 & 0.797 & 0.834 & 0.852 & 0.863 \\
1974 & 0.748 & 0.798 & 0.914 & 0.954 & 0.972 & 0.981 \\
1975 & 0.641 & 0.705 & 0.720 & 0.745 & 0.748 & 0.748 \\
1976 & 0.657 & 0.727 & 0.855 & 0.866 & 0.865 & \\
1977 & 0.695 & 0.884 & 0.972 & 0.967 & & \\
1978 & 0.698 & 0.822 & 0.871 & & & \\
1979 & 0.746 & 0.823 & & & & \\
1980 & 0.758 & & & & & \\
\hline
\end{tabular}

From this triangle a steady growth in loss ratios over development years is observed, but it is not assessed as easily as in the case of premiums. Again, the logarithmic increments describe the developments in a more easily intelligible manner:

TABLE V

LOGARITHMIC INCREMENTS OF LOSS QUOTIENTS

\begin{tabular}{cccccr}
\hline \hline & \multicolumn{5}{c}{ Development Year } \\
\cline { 2 - 6 } $\begin{array}{c}\text { Underwriting } \\
\text { Year }\end{array}$ & $1 \rightarrow 2$ & $2 \rightarrow 3$ & $3 \rightarrow 4$ & $4 \rightarrow 5$ & $5 \rightarrow 6$ \\
\hline 1970 & & & & 0.014 & -0.008 \\
1971 & & & -0.007 & -0.010 & 0.006 \\
1972 & & 0.139 & 0.045 & 0.021 & 0.013 \\
1973 & 0.065 & 0.135 & 0.044 & 0.018 & 0.009 \\
1974 & 0.096 & 0.021 & 0.035 & 0.004 & 0.000 \\
1975 & 0.102 & 0.162 & 0.013 & -0.002 & \\
1976 & 0.241 & 0.095 & -0.006 & & \\
1977 & 0.164 & 0.057 & & & \\
1978 & 0.098 & & & & \\
1979 & 0.128 & 0.102 & 0.021 & 0.007 & 0.005 \\
& 0.0643 & 0.0542 & 0.0238 & 0.0121 & 0.0082 \\
mean & 5 & 5 & 5 & 5 & 5 \\
std. deviation & & & & & \\
dgs. of freedom & & & & & \\
\hline
\end{tabular}

It is seen that standard deviations of the loss quotient increments are larger than the ones of premium increments. This means that loss quotient developments 
are subject to more fluctuations than premiums, as should be expected taking the ceding company's need to reinsure its portfolio into consideration.

The study of loss quotient development patterns met some difficulties owing to the quality of our data, since registrations up to 1980 have been manual, not meeting the requirements of a computerized analysis. Apart from cases involving cumbersome data problems, stability of logarithmic increments turned not to be a general phenomenon of our sample treaties. No marked patterns of interdependence between increments of premiums and of loss ratios could be detected and only slight signs of a negative autocorrelation between increments of consecutive development years could be observed.

Description of the loss ratio developments by stable logarithmic increments implies that shifts in rate level will affect the level of loss ratios but not the development pattern. So a high loss quotient in an early development year indicates an underwriting year growing proportionately worse. To the extent that claims of a reinsurance treaty are made up by a considerable number of individual claims allowing for smoothing, this reasoning is a correct model of reality. But large claims, as a total loss of a vessel, are in general readily reported and not affecting the subsequent smooth development of ordinary claims. For this reason large claims should be registered separately and not included in the loss ratio applied in establishment of IBNR-reserves.

Unfortunately large claims were not registered separately in the Baltica files, thus causing problems in the model fitting analysis.

\section{ESTIMATION OF THE RUN OFF PATTERN}

If we call the loss quotients $Q$, and number the underwriting years by $i$ and the development years by $j$, we have

$$
\begin{aligned}
Q_{i j}= & \text { loss quotient of underwriting year } i \text { at the end } \\
& \text { of development year } j \\
i= & 69, \ldots, 80, \ldots \\
j= & 1, \ldots, 6
\end{aligned}
$$

and we have the logarithmic increments

$$
d q_{i j}=\log \left(Q_{i, j+1} / Q_{i, j}\right), \quad j=1, \ldots, 5 .
$$

Then the examination of data suggests use of the normal distribution

$$
d q_{i j} \sim N\left(\zeta_{j}, \sigma_{j}^{2}\right) \text { independently }
$$

the parameters $\zeta_{j}$ and $\sigma_{j}^{2}$ being estimated by

$$
\begin{aligned}
& \hat{\zeta}_{j}=\left(\Sigma_{i} d q_{i j}\right) / N_{j} \sim N\left(\zeta_{j}, \sigma_{j}^{2} / N_{j}\right) \\
& \hat{\sigma}_{j}^{2}=\Sigma_{i}\left(d q_{i j}-\hat{\zeta}_{j}\right)^{2} /\left(N_{j}-1\right) \sim \sigma_{j}^{2} \chi^{2}\left(f_{j}\right) / f_{j}, \quad f_{j}=N_{j}-1
\end{aligned}
$$

where $N_{j}$ is the number of observed increments from development year $j$ to $j+1$. It follows from the theory that the $\hat{\zeta}_{j}$ and $\hat{\sigma}_{j}^{2} j=1, \ldots, 5$ are mutually independent. 
By these parameters we have obtained a description of the run-off pattern of the treaty. It should be noted that the parameters describe the one-step increments, thus allowing for estimation exploiting all data observed, including the latest observations. With more abundant data, an alternative description could be obtained by the logarithmic increment from present to ultimate stage. A such description would be advantageous in the forecasting procedure but is of little practical interest at present circumstances. Whichever description is applied, it can be used to test identity of run-off patterns by one-way analysis of variance. In the sample treaties only highly significant results were obtained, indicating individuality of treaties.

\section{FORECASTING THE DEVELOPMENT OF A TREATY}

Having observed underwriting year $i$ at the $P$ 'th development year, the objective to forecast the ultimate loss ratio

$$
Q_{i}=Q_{i, \infty}=Q_{i, 6}
$$

is obtained by application of the previous chapters.

From the normality of $d q_{i, j}$ follows that the conditional distribution of $Q_{i}$ given $Q_{i, p}$

$$
Q_{i}\left|Q_{i, p}=Q_{i \mid p}=Q_{i, p} \exp \left(d q_{i, p}+\cdots+d q_{i, 5}\right)\right| Q_{i, p}
$$

is lognormal with logarithmic mean and variance

$$
\begin{aligned}
E\left[\log Q_{i \mid p}\right] & =E\left[\log Q_{i, p}+d q_{i, p}+\cdots+d q_{i, 5} \mid Q_{i, p}\right] \\
& =\log Q_{i, p}+\zeta_{p}+\cdots+\zeta_{5} \\
\operatorname{Var}\left[\log Q_{i \mid p}\right] & =\operatorname{Var}\left[\log Q_{i, p}+d q_{i, p}+\cdots+d q_{i, 5} \mid Q_{i, p}\right] \\
& =\sigma_{p}^{2}+\cdots+\sigma_{5}^{2} .
\end{aligned}
$$

If the parameters $\zeta_{p}, \ldots, \zeta_{5}$ and $\sigma_{p}^{2}, \ldots, \sigma_{5}^{2}$ were known (5.3) might be applied as a forecast, to be evaluated in the normal distribution with variance (5.4). Now, the parameters are unknown and we have to substitute the estimates $\hat{\zeta}_{p}, \ldots, \hat{\zeta}_{s}$. So the individual logarithmic increments $d q_{i, j}$ are forecasted by the $\hat{\zeta}_{j}$

$$
\begin{gathered}
d q_{i, j}=\zeta_{j}+\varepsilon_{i, j}=\hat{\zeta}_{j}+\left(\zeta_{j}-\hat{\zeta}_{j}\right)+\varepsilon_{i, j}=\hat{\zeta}_{j}+\phi_{i, j}+\varepsilon_{i, j}, \\
\phi_{i, j} \sim N\left(0, \sigma_{j}^{2} / N_{j}\right), \quad \varepsilon_{i, j} \sim N\left(0, \sigma_{j}^{2}\right),
\end{gathered}
$$

thus introducing a forecasting error consisting of an estimation error $\phi_{i, j}$ and a pure forecasting error $\varepsilon_{i, j}$. We obtain a forecast of $Q_{i}$ by

$$
\tilde{Q}_{i \mid p}=Q_{i, p} \exp \left(\hat{\zeta}_{p}+\cdots+\hat{\zeta}_{5}\right)
$$

which is lognormally distributed with logarithmic mean and variance

$$
\begin{aligned}
E\left[\log \tilde{Q}_{i \mid p}\right] & =\log Q_{i, p}+E\left[\hat{\zeta}_{p}+\cdots+\hat{\zeta}_{5}\right] \\
& =\log Q_{i, p}+\zeta_{p}+\cdots+\zeta_{5},
\end{aligned}
$$




$$
\begin{aligned}
\operatorname{Var}\left[\log \tilde{Q}_{i \mid p}\right] & =\operatorname{Var}\left[\phi_{i, p}+\varepsilon_{i, p}+\cdots+\phi_{5, p}+\varepsilon_{5, p}\right] \\
& =\sigma_{p}^{2} \frac{N_{p}+1}{N_{p}}+\cdots+\sigma_{5}^{2} \frac{N_{5}+1}{N_{5}} .
\end{aligned}
$$

Now, the lognormal distribution with logarithmic mean $\mu$ and variance $\sigma^{2}$ is right skew with

$$
\begin{array}{ll}
\text { mean: } & \exp \left(\mu+\sigma^{2} / 2\right) \\
\text { median: } & \exp (\mu) \\
\text { std. deviation: } & \exp \left(\mu+\sigma^{2} / 2\right) \sqrt{\exp \sigma^{2}-1}
\end{array}
$$

and so a central forecast of $Q_{i}$ is supplied by

$$
\hat{Q}_{i \mid p}=Q_{i, p} \exp \left(\hat{\zeta}_{p}+\cdots+\hat{\zeta}_{s}\right) \exp \left(\sigma_{(p)}^{2} / 2\right)
$$

with

$$
\sigma_{(p)}^{2}=\hat{\sigma}_{p}^{2} \frac{N_{p}+1}{N_{p}}+\cdots+\hat{\sigma}_{5}^{2} \frac{N_{5}+1}{N_{5}}
$$

\begin{tabular}{|c|c|c|c|c|c|c|c|c|}
\hline \multirow{2}{*}{$\begin{array}{c}\text { Underwriting } \\
\text { Year }\end{array}$} & \multicolumn{6}{|c|}{ Year of Development } & \multicolumn{2}{|c|}{ Forecast } \\
\hline & 1 & 2 & 3 & 4 & 5 & 6 & $\hat{Q}_{i \mid p}$ & $s$ \\
\hline 1969 & & & & & & 0.801 & & \\
\hline 1970 & & & & & 0.781 & 0.791 & & \\
\hline 1971 & & & & 0.724 & 0.734 & 0.728 & & \\
\hline 1972 & & & 0.762 & 0.756 & 0.749 & 0.753 & & \\
\hline 1973 & & 0.694 & 0.797 & 0.834 & 0.852 & 0.863 & & \\
\hline 1974 & 0.748 & 0.798 & 0.914 & 0.954 & 0.972 & 0.981 & & \\
\hline 1975 & 0.641 & 0.705 & 0.720 & 0.754 & 0.748 & 0.748 & & \\
\hline 1976 & 0.657 & 0.727 & 0.855 & 0.866 & 0.865 & & 0.869 & 0.008 \\
\hline 1977 & 0.695 & 0.884 & 0.972 & 0.967 & & & 0.979 & 0.015 \\
\hline 1978 & 0.698 & 0.822 & 0.871 & & & & 0.901 & 0.027 \\
\hline 1979 & 0.746 & 0.823 & & & & & 0.944 & 0.062 \\
\hline 1980 & 0.758 & & & & & & 0.991 & 0.096 \\
\hline
\end{tabular}

the variance of the forecast being estimated by

$$
\operatorname{Var}\left[\hat{Q}_{i \mid p}\right]=\hat{Q}_{i \mid p} \sqrt{\exp \sigma_{(p)}^{2}-1}
$$

Applied to the example marine treaty the forecasted loss quotients may be presented by insertion in the run off triangle (2.4)

Loss Quotients OBSERved AND Forecasts

$s$ denotes the standard deviation of the forecast.

These forecasted loss quotients offer a help to the assessment of rate levels of still developing underwriting years. 
Applying an identical model to the premiums produces the forecasts:

Premiums OBSERVED AND Forecasts

\begin{tabular}{|c|c|c|c|c|c|c|c|c|}
\hline \multirow{2}{*}{$\begin{array}{c}\text { Underwriting } \\
\text { Year }\end{array}$} & \multicolumn{6}{|c|}{ Year of Development } & \multicolumn{2}{|c|}{ Forecast } \\
\hline & 1 & 2 & 3 & 4 & 5 & 6 & $\hat{p}_{i \mid p}$ & $s$ \\
\hline 1969 & & & & & & 226 & & \\
\hline 1970 & & & & & 261 & 261 & & \\
\hline 1971 & & & & 329 & 328 & 328 & & \\
\hline 1972 & & & 434 & 436 & 435 & 435 & & \\
\hline 1973 & & 610 & 632 & 631 & 630 & 630 & & \\
\hline 1974 & 420 & 704 & 739 & 738 & 736 & 736 & & \\
\hline 1975 & 310 & 598 & 629 & 624 & 623 & 622 & & \\
\hline 1976 & 310 & 599 & 629 & 631 & 629 & & 629 & 0.1 \\
\hline 1977 & 345 & 667 & 680 & 679 & & & 678 & 0.7 \\
\hline 1978 & 491 & 731 & 737 & & & & 734 & 3.2 \\
\hline 1979 & 581 & 815 & & & & & 842 & 16.4 \\
\hline 1980 & 577 & & & & & & 1033 & 162.8 \\
\hline
\end{tabular}

For a single underwriting year, the forecasts $\hat{P}_{i \mid p}$ and $\hat{Q}_{i \mid p}$ may be assumed independent.

\section{SETTING UP IBNR-RESERVES FOR A SINGLE TREATY}

From the forecasts $\hat{P}_{i \mid p}$ of the ultimate premium and $\hat{Q}_{i \mid p}$ of the ultimate loss ratio, of underwriting year $i$ observed at the $P$ th development year, a forecast of the ultimate financial result is derived.

With a fixed commission rate $w$ the relation between ultimate premium $P_{i}$, loss ratio $Q_{i}$ and financial result $R_{i}$ is

$$
R_{i}=P_{i}-w P_{i}-Q_{i} P_{i}=P_{i}\left(1-w-Q_{i}\right) .
$$

Inserting estimates $\hat{P}_{i \mid p}$ and $\hat{Q}_{i \mid p}$ in (6.1) yields a forecast of $R_{i}$, whose distribution is of lognormal type, but translated and reversed on the real line. This distribution is easily studied, though involving some arithmetic complexity.

The larger part of variation in this forecast of $R_{i}$ is caused by $\hat{Q}_{i \mid p}$, as the variance of $P_{i \mid p}$ is in general much smaller than that of $\hat{Q}_{i \mid p}$. Further, extraneous information on the ultimate premium volume $P_{i}$ is usually provided by cedants, allowing heuristic improvements of the premium forecast by combination of $\hat{P}_{i \mid p}$ and the cedant's information. Evaluation of $R_{i}$ in the conditional distribution given $P_{i}$ models this administrative procedure loosing only a small variance component, and so the conditional forecast of $R_{i}$ is applied:

$$
\hat{R}_{i \mid p}=P_{i}-w P_{i}-\hat{Q}_{i \mid p} P_{i} \mid P_{i}
$$

In this conditional distribution the stochastic element remaining is the volume of claims $\hat{Q}_{i \mid p} P_{i}$ which is lognormally distributed, and from this distribution confidence limits for $\hat{R}_{i \mid p}$ may be derived. Again the normal approximation with 
estimated standard deviation

$$
\hat{Q}_{i \mid p} P_{i} \sqrt{\exp \sigma^{2}-1}
$$

supplies an indication of the precision of $\hat{\boldsymbol{R}}_{i \mid p}$, for the use of practitioners. Also, the normal approximation is useful when treaties are aggregated to a portfolio.

Applying this normal approximation we obtain forecasts of the sample treaty's open underwriting years

Forecasted Ultimate Results

\begin{tabular}{cccccc}
\hline $\begin{array}{c}\text { Underwriting } \\
\text { Year }\end{array}$ & Premium & Commission & Claims & $\begin{array}{c}\text { Financial } \\
\text { Result }\end{array}$ & $\begin{array}{c}\text { Standard } \\
\text { Deviation }\end{array}$ \\
\hline 1976 & 629 & 173 & 547 & -91 & 4.4 \\
1977 & 678 & 186 & 664 & -172 & 10.0 \\
1978 & 734 & 202 & 661 & -129 & 17.9 \\
1979 & 842 & 232 & 795 & -185 & 49.3 \\
1980 & 1033 & 284 & 1024 & -275 & 98.3 \\
\hline
\end{tabular}

The IBNR-reserve is the supplementary reserve needed to match the results on books with anticipated ultimate results, in the example:

\begin{tabular}{|c|c|c|c|c|c|c|}
\hline \multirow{2}{*}{$\begin{array}{l}\text { Accounts and } \\
\text { forecasted results of } \\
\text { underwriting years }\end{array}$} & \multicolumn{6}{|c|}{ Underwriting year } \\
\hline & 75 & 76 & 77 & 78 & 79 & 80 \\
\hline \multicolumn{7}{|c|}{ Booked at the end of 1980} \\
\hline Premium & 622 & 629 & 679 & 737 & 815 & 577 \\
\hline Commission & 171 & 173 & 187 & 203 & 224 & 159 \\
\hline Claims paid & 462 & 492 & 593 & 585 & 520 & 174 \\
\hline Claims outstanding & 3 & 52 & 64 & 57 & 151 & 263 \\
\hline IBNR-reserve & 0 & 3 & 7 & 21 & 105 & 256 \\
\hline Financial result & -14 & -91 & -172 & -129 & -185 & -275 \\
\hline \multicolumn{7}{|c|}{ Forecasted ultimate accounts } \\
\hline Premium & 622 & 629 & 678 & 734 & 842 & 1033 \\
\hline Commission & 171 & 173 & 186 & 202 & 232 & 284 \\
\hline Claims & 465 & 547 & 664 & 661 & 795 & 1024 \\
\hline Financial result & -14 & -91 & -172 & -129 & -185 & -275 \\
\hline Commission rate & 0.275 & 0.275 & 0.275 & 0.275 & 0.275 & 0.275 \\
\hline Loss quotient & 0.748 & 0.869 & 0.979 & 0.901 & 0.944 & 0.991 \\
\hline $\begin{array}{l}\text { Standard deviation } \\
\text { of loss quotient }\end{array}$ & 0.0 & 0.008 & 0. & 0.027 & 0.062 & 0.096 \\
\hline
\end{tabular}

7. SETTING UP IBNR-RESERVES FOR A PORTFOLIO

Due to developments in portfolio composition from one underwriting year to the next, application of the procedure of the previous chapters on aggregate run-off triangles of a portfolio is less accurate than the summation of IBNRreservestablished at individual treaties. Also, use of individual IBNR-reserves 
facilitates the inclusion of explicit non-statistical information, and tracing the influence of important individual cases. Both facilities are essential to the transparency of the procedure to non-statisticians, and thus to the attainment of confidence by management.

In probabilistic terms the log normal distributions of the individual IBNRreserves are smoothed in the summation to portfolio level, by the law of large numbers. So, the distributions of the portfolio reserves are not lognormal. Provided the portfolio consists of sufficiently many similar treaties, the normal approximation offers a reasonable assumption for evaluation of the portfolio reserves.

If the estimated IBNR-reserve of treaty $x$, underwriting year $i$ is

$$
\hat{R}_{i}(x)
$$

with standard deviation $s_{i}(x)$ obtained by (6.3), we obtain the portfolio IBNRreserve of underwriting year $i$

$$
\hat{R}_{i}(\cdot)=\Sigma_{x} \hat{R}_{i}(x)
$$

with standard deviation

$$
s_{i}(\cdot)=\left(\Sigma_{x} s_{i}^{2}(x)\right)^{1 / 2} .
$$

Correspondingly, the total IBNR-reserve over all underwriting years is

$$
\begin{aligned}
& \hat{R} .(\cdot)=\Sigma_{i} \Sigma_{x} \hat{R}_{i}(x) \\
& \text { s. }(\cdot)=\left(\Sigma_{i} \Sigma_{x} s_{i}^{2}(x)\right)^{1 / 2} .
\end{aligned}
$$

Some traditions of reserving procedures seem to argue for a security loading of reserves, the explicit meaning of which is not always clear. With a statistical approach, the security loading will be related to a confidence interval, and so the security loading should be proportional to the portfolio standard deviation (7.3) or (7.5) rather than the volume of reserves (7.2) or (7.4), or the premium. A proper security loading of individual treaties would turn out to be costly at a reasonable confidence level, and it should lead to systematic overreserving of the portfolio.

Security loading may conveniently take the shape of a contingency reserve established as a percentage point in the distribution of $R(\cdot)$. Exploiting the normal approximation the contingency reserve at security level $99 \%$ is $2.326 s(\cdot)$ and at level $99.9 \%$ it is $3.090 s(\cdot)$. If required for administrative reasons, the contingency reserve may be distributed on underwriting years, subfolios or individual treaties according to their standard deviations (7.3), thus ensuring a common security level of all components of the split.

\section{TESTING PARAMETER STABILITY}

Application of methods as described above require data input of high quality, and checking for instabilities. Ordinary statistical procedures are useful for this purpose. 
Observing a new logarithmic increment $d q_{i, j}$ of loss quotients from the $j$ th to the $j+1$ st development year this can be evaluated against the previous parameter estimates $\hat{\zeta}_{j}$, $\hat{\sigma}_{j}^{2}$ by a Student's $t$-test:

$$
t_{i, j}=\left(d q_{i, j}-\hat{\zeta}_{j}\right) / \hat{\sigma}_{j} \sqrt{\left(N_{j}+1\right) / N_{j}} \sim t\left(f_{j}\right), \quad N_{j} \geqslant 2
$$

and it can be shown that the $t$-values

$$
t_{3, j}, t_{4, j}, \ldots, t_{N_{j, j}}
$$

are mutually independent and independent of the new parameter estimates $\hat{\zeta}_{j}$, $\hat{\sigma}_{j}^{2}$. So these $t$-values supply a basis for testing parameter stability.

\section{UNIFICATION OF STATISTICAL PROCEDURES AND UNDERWRITING INFORMATION}

Application of the described statistical procedure may seem just straight-forward, but is not so. The very important aspect of including non-statistical information should be considered in any implementation of scientifically based procedures. In many cases underwriters will be able to explain a significant shift in parameters, in other cases some known changes must be taken into consideration though not yet evident in data, and in still other cases a $t$-test may draw the attention of underwriters to some unnoticed phenomenon. In any case, a careful study of the composition of portfolio results should be carried out and appropriate corrections accomplished, to obtain a unification of statistically based indications and general information.

\section{OPEN ENDS}

Though the log normal distribution supplies a useful tool, its validity in a strict sense may be doubted. In the sample data loosely referred to in this paper, the tail of the log normal appeared somewhat too thick, leading to use of a median forecast $\exp (\hat{\zeta})$ instead of the mean value forecast $\exp \left(\hat{\zeta}+\sigma^{2} / 2\right)$ in practical applications.

A further study into the shape of distributions involved is desirable, in search of a distribution allowing aggregation from single risks to a reinsurance treaty and from treaties to a reinsurance portfolio, as well as a distribution fitting high quality data well.

Treaties with a firm run-off pattern, i.e., small variances $\sigma_{j}^{2}$ of logarithmic increments might be used as indicators of tendencies affecting each treaty in the portfolio. This may lead to the inclusion of credibility theory as described for instance by NORBERG (1979).

A last point is the explicit inclusion of interest and inflation into the procedure. This requires accountancy considerations and definitions well beyond the scope of the present paper, but still any insurer operating in long-tail insurance must pay attention to this aspect of business. 


\section{ACKNOWLEDGEMENTS}

The paper has benefited from discussion with assistant professor Henrik Ramlau-Hansen of University of Copenhagen, chief marine underwriter Finn Clausen of B-N Re and chief actuary Jens Erik Christensen of Baltica. Without the continuing support and encouragement of Jens Erik Christensen the paper would not have been set on print.

\section{REFERENCES}

BüblmanN H., SChNiePer R. and Straub E. (1980) Claims Reserves in Casuality Insurance based on a Probabilistic Model. Mitteilungen der Vereinigung Schweizerischer Versicherungsmathematiker 1, 21-45.

KREMER, F. (1982) IBNR-claims and the Two-way model of ANOVA. Scandinavian Actuarial Journal 47-55.

NORBERG, R. (1979) The Credibility Approach to Experience Rating. Scandinavian Actuarial Journal $181-221$

TAYLOR, G. C. (1977) Separation of Inflation and Other Effects from the Distribution of Non-Life Insurance Claim Delays. Astin Bulletin 9, 217-230. 